\title{
Model Pengendalian Internal Pesantren
}

\author{
Abd. Mujib ${ }^{1)}$, Siti Maria Wardayati ${ }^{2)}$, Muhammad Miqdad ${ }^{3)}$ \\ ${ }^{1}$ Mahasiswa Magister Akuntansi Fakultas Ekonomi dan Bisnis, Universitas Jember, Indonesia \\ ${ }^{2,3}$ Fakultas Ekonomi dan Bisnis, Universitas Jember, Indonesia \\ *Email korenpondensi: abede.abiradiv@gmail.com
}

\begin{abstract}
This research aims to produce a model of internal control at Pesantren as an educational institution that upholds the values of Islamic culture and traditions. In managing its organization, each entity has the same potential to correct fraud. One of supports expected to be able to prevent fraud and become an effective means to achieve goals is the internal control. The qualitative researchis conducted with a strategy grounded theory at Pondok Pesantren Salafiyah Syafi'iyah Sukorejo. The results of this study found that the unique element of Pesantren is the value of spirituality that underlies all activities. These elements of spirituality are categorized as the following, namely 1) the categories of beliefs and attitudes consisting of iman, akhlak, amanah, spiritual connection and barokah, 2) practice consisting of niat, khidmah, musyawarah and istikharah, 3) management consisting of Pengasuh Pesantren, centralization and salaf-khalaf, and 4) pesantren heritage consisting of ibadah, wirid, hizib and istiqamah. These spiritual elements become effective fortress for pesantren in carrying out all its activities, and are named Spiritual-based Internal Control.
\end{abstract}

\section{Keywords : Fraud and Prevention, Internal Control, Pondok Pesantren, Spirituality}

Saran sitasi: Mujib, A., Wardayati, S. M., \& Miqdad, M. (2021). Model Pengendalian Internal Pesantren. Jurnal Akuntansi dan Pajak, 21 (2), 306-320. doi: http://dx.doi.org/10.29040/jap.v21i2.1319

DOI: http://dx.doi.org/10.29040/jap.v21i2.1319

\section{PENDAHULUAN}

Dalam budaya Pondok Pesantren, dikenal sebuah kaidah ushul fiqh, almuhaafadzotu 'alal qodiimish shoolih wal akhdu bil jadiidil ashlah. Kaidah ini menjadi salah satu motivasi yang mendasari landasan berpikir kaum santri dalam menghadapi setiap perkembangan zaman. Saat ini santri tidak cukup dibekali aspek moral dan akhlak saja, namun perlu dibekali keahlian dan keterampilan yang relevan dengan tuntutan zaman. Perhatian untuk mempelajari sain-teknologi semakin besar, di samping tetap istiqamah fokus pada ilmu agama dan akhlakul karimah. Fenomena ini menyiratkan besarnya kesadaran pesantren dalam merespon tuntutan zaman (Suwadji, 2014).

Perubahan yang terjadi meniscayakan adanya penguatan manajemen pengelolaan di pesantren, hal ini penting agar pesantren dapat memberikan peran yang proporsional pada sisi kultural dan strukturalnya. Sisi keuangan adalah salah satu aspek yang perlu diperhatikan, karena di sinilah sisi yang rawan konflik dan sangat menentukan eksistensi suatu lembaga.
Maka, manajemen keuangan pondok pesantren yang baik mutlak dibutuhkan (Yakin, 2014). Bahkan, pemerintah melalui Bank Indonesia memberikan perhatian khusus dengan menerbitkan Pedoman Akuntansi Pesantren agar pondok pesantren secara bertahap dapat menyesuaikan laporan keuangannya berdasarkan standar akuntansi keuangan yang berlaku umum dengan tidak mengabaikan karakteristiknya (Bank Indonesia, 2018).

Pesantren saat ini telah memiliki struktur organisasi yang lebih kompleks, hal ini seiring dengan semakin banyaknya lembaga pendidikan yang didirikan. Masing-masing lembaga diberi kewenangan mengelola kebutuhan operasionalnya (Tandiontong, 2016). Dari sinilah kemudian muncul hubungan yang dikenal antara agent dan principal sebagaimana teori agency (Jensen dan Meckling, 1976). Sebagai penerima amanat, pengelola lembaga sudah semestinya menunjukkan loyalitas kepada pimpinannya dalam struktur pesantren (Hartadi, 1999), tidak boleh khianat, mengabaikan tugas atau mementingkan diri sendiri (Djajadikerta, 2004). Hal 
ini penting ditekankan, mengingat hasil riset menunjukkan bahwa mayoritas fraud dilakukan oleh manajemen (Kasim, 2010) dan penggelapan oleh karyawan (Niswonger, dkk., 1990).

Namun begitu, semua entitas memiliki potensi yang sama mengalami fraud. Tidak ada satu entitas pun di dunia ini yang terbebas dari potensi fraud (Mujib, 2017b) yang akan terus ada, seberapa pun kuatnya orang-orang berusaha keras mencegahnya (Rahman dan Anwar, 2014). Pelaku fraud tidak terbatas pada kelompok tertentu, semua berpeluang menjadi pelaku, karena yang menjadi fokus adalah bagaimana mendapatkan keuntungan, baik untuk pribadi dan atau kelompoknya (Priantara, 2013). Simbol agama tidak dapat menjadi jaminan bahwa sebuah entitas akan pasti terbebas dari potensi fraud (Sula, dkk., 2004).

\subsection{Fraud dan Pencegahannya}

Fraud adalah ketidakberaturan dan penyimpangan (Priantara, 2013), penipuan, kebohongan, ketidakjujuran dan kelalaian yang disengaja dengan maksud untuk menipu dan menghilangkan hak milik orang lain (Arens, dkk., 2012) yang mengakibatkan korbannya mengalami kerugian atau pelakunya mendapatkan keuntungan (Reding, dkk., 2013). Kata kuncinya adalah kesengajaan (intentional), untuk membedakannya dengan kelalaian (negligence) dan kekeliruan (error) yang merupakan bentuk ketidaksengajaan (unintentional) (Priantara, 2013). Kesalahan yang disengaja adalah bentuk dari fraud dan kejahatan, sedangkan kesalahan yang tidak disengaja merupakan sunnatullah, keniscayaan bagi manusia sebagai makhluk tempatnya salah dan lupa. Namun begitu, keduanya dapat menyebabkan kerugian, baik keuangan, administrastif, atau kerugian lain yang tetap harus dihindari (Hartadi, 1999).

Semua entitas memiliki potensi yang sama mengalami kejadian fraud di dalamnya, tiada satu pun entitas yang benar-benar imun atau kebal dari fraud (Mujib, 2017b). Sekuat apa pun berusaha dicegah, potensi fraud akan terus ada (Rahman dan Anwar, 2014). Terlebih, mereka yang mengetahui kelemahan organisasi memiliki kesempatan yang lebih besar untuk melakukan fraud, apalagi jika memiliki posisi, fungsi dan otorisasi dalam organisasi (Wolfe dan Hermanson, 2004). Maka cukup beralasan bahwa manajemen menjadi elemen mayoritas sebagai pelaku fraud dibandingkan pihak eksternal (Kasim, 2010).
Fraud sudah ada sejak adanya proses transaksi perdagangan, namun secara akademis baru muncul pada tahun 1776 oleh Adam Smith yang mencetuskan konsep early fraud (Dorminey, dkk., 2012), dilanjutkan konsep white collar crime (1939) (Priantara, 2013), pada 1953 Donald Cressey melahirkan konsep fraud yang paling terkenal, The Fraud Triangle, kemudian fraud scale model (1984) (Kassem dan Higson, 2012), The Fraud Diamond (2004) (Wolfe dan Hermanson, 2004), The Triangle of Fraud Action (2006) (Dorminey, dkk., 2012), The ABC Model (2009) (Ramamoorti, dkk., 2009), model M.I.C.E. (2010), fraud predator (2010), New Fraud Diamond (2012) (Dorminey, dkk., 2012), selanjutnya The New Fraud Triangle Model (2012) (Kassem dan Higson, 2012), dan yang terakhir adalah Sharia Fraud Model (Mujib, 2017a).

Fenomena fraud yang terungkap bagaikan fenomena gunung es, yang tampak hanya permukaannya, sedangkan yang terendam di dalam lautan jauh lebih besar (Priantara, 2013), bahkan cenderung disembunyikan. Karena tidak ada satu pun entitas yang terbebas dari potensi fraud, maka yang terpenting adalah upaya pencegahan yang ditingkatkan semaksimal mungkin. Langkah-langkah pembenahan dan pengawasan perlu dilakukan secara terus-menerus untuk memastikan perjalanan organisasi sesuai dengan role yang telah ditentukan sehingga tujuan dapat dicapai. Walau memang, sebaik apa pun sebuah sistem diciptakan, langkah pengamanan dibuat berlapis seperti apa pun, potensi terjadinya penyelewengan tetap selalu ada, bahkan bagi mereka yang telah memiliki watak fraud tidak akan kehilangan akal untuk mencari celah kelemahan sebuah sistem (Mujib, 2017a).

Dari sekian banyak literatur, terdapat satu kesamaan pandangan bahwa sistem pengendalian internal sebuah organisasi merupakan instrumen yang vital dan efektif untuk mencegah terjadinya fraud, dan diyakini dapat menjadi salah satu sarana yang efektif bagi organisasi dalam mencapai tujuan, memitigasi resiko, dan membantu memastikan efektivitasefisiensi operasional (Murtanto, 2005; Lakis dan Giriunas, 2012; Aviana, 2012; Tunggal, 2013; Sanusi, dkk., 2015; DiNapoli, 2016). Organisasi yang tidak memiliki sistem pengendalian internal, atau punya namun lemah, maka peluang terjadinya fraud sangat besar (Priantara, 2013; Nisak, dkk., 2013). Semakin hari, pengendalian internal semakin dipandang sebagai solusi terhadap berbagai masalah potensial 
yang mungkin terjadi di sebuah organisasi (Murtanto, 2005).

\subsection{Internal Control}

Konsep pengendalian internal yang banyak diadopsi di berbagai negara termasuk di Indonesia adalah model COSO (COSO, 2013). Selain COSO (Committee of Sponsoring Organizations of the Treadway Commission) di USA, yang juga banyak dikenal adalah CoCo (Criteria of Control Board of the Canadian Institute of Chartered Accountants) di Kanada dan Cadbury Commission di Inggris (Tunggal, 2013).

Istilah internal control pertama kali muncul pada 1949 oleh American Institute of Certified Public Accountants (AICPA) yang mendefinisikan pengendalian internal sebagai rencana, sarana koordinasi lainnya dan cara yang dilakukan oleh entitas untuk menjaga keamanan aset, memeriksa kerahasiaan dan keandalan data, meningkatkan efektivitas serta menentukan politik manajemen. Pada 1992 COSO muncul yang mendefinisikan internal control sebagai prosedur eksekutif bagi dewan direksi, pemilik otoritas, dan karyawan lainnya untuk mencapai tujuan organisasi dengan memenuhi efektivitas dan efisiensi operasional, laporan keuangan yang andal, serta ketaatan pada peraturan dan regulasi (Lakis dan Giriunas, 2012).

Dari semua definisi yang beraneka ragam dari berbagai sudut pandang, secara sederhana dapat dipahami bahwa internal control adalah satu-kesatuan sistem yang utuh yang berisi seluruh kebutuhan untuk mencapai tujuan, serta mencegah, mendeteksi, dan memperbaiki potensi kesalahan. Internal control diharapkan dapat menjadi ujung tombak dalam melindungi aset dengan mencegah terjadinya pencurian, penyalahgunaan, atau penempatan di lokasi yang tidak semestinya (Niswonger, dkk., 1990).

Sistem pengendalian internal dalam konteks yang lebih luas dapat dimaknai sebagai seluruh dinamika yang terjadi di dalam organisasi, baik yang dilakukan oleh pihak internal atau pun eksternal yang dimaksudkan untuk memastikan tercapainya tujuan organisasi. Kata kunci utamanya adalah tujuan organisasi.

Internal control merupakan sebuah sistem yang saling terkait dan menyatu dalam seluruh rancang bangun organisasi yang dirancang dengan maksud untuk memastikan tercapainya tujuan organisasi yang merupakan tanggung jawab manajemen (Tunggal, 2013). Sebagai sebuah sistem, internal control haruslah mencakup seluruh aspek organisasi (Lakis dan Giriunas, 2012), tidak boleh ada yang terlewatkan. Karakteristik dasar pengendalian internal bersifat kompleks dan terdiri atas seluruh aktivitas organisasi, baik ke samping, ke atas, ke bawah, ke dalam dan keluar organisasi (Pfister, 2009). Idealnya, semua aturan dan kebijakan tertata rapi dalam dokumen tertulis agar dapat dipelajari dan dipedomani (Daniela dan Atilla, 2013).

Internal control yang baik tidak hanya bertujuan untuk melindungi organisasi, namun sekaligus untuk memastikan keamanan dan keamanahan seluruh elemen yang terlibat di dalamnya. Internal control tidak hanya terdiri atas pedoman, peraturan, kebijakan dan formulir, namun berkaitan erat pula dengan sumber daya manusia yang menjalankan dan mempengaruhinya di semua level organisasi (Mulyadi, 2014). Setiap personil bertanggung jawab penuh atas tugas dan kewajibannya. Sistem pengendalian dapat terdiri dari subsistem pengendalian di tingkatan yang lebih kecil dan teknis. Masing-masing secara sistemik merupakan pengendalian bagi subsistem yang lain serta dapat mengevaluasi efektivitas pengendalian yang lain (Tunggal, 2013). Sebagai sistem, semua saling terkait dan berdampak sebab-akibat.

Tidak semua orang jujur dan berintegritas tinggi. Sebaik apa pun aturan dan prosedur disusun, semua akhirnya kembali juga kepada kapasitas manusianya yang dapat dilihat dari rata-rata pendidikan, pelatihan dan tingkat pengalamannya (Delanno dan Deviani, 2013). Sistem pengendalian internal harus disusun sedemikian rupa sehingga dapat mendorong manusianya untuk berbuat jujur atau dipaksa berbuat jujur. Pengendalian yang baik akan menjadi rusak dan tidak berguna jika diisi oleh orang yang buruk, yang melakukan kolusi atau menolak adanya pengendalian (Tunggal, 2013).

Manusia adalah aspek terpenting dalam internal control. Jika kompeten dan jujur, maka komponen kontrol lainnya dapat dikurangi atau ditiadakan, namun jika sebaliknya, maka sebanyak apa pun kontrol tidak akan banyak berarti (Arens, dkk., 2012). Faktor inti yang paling sulit dalam sistem pengendalian adalah keberadaan orang-orang yang tepat yang dapat menunjang agar sistem dapat beroperasi dengan optimal. Orang-orang terbaik cenderung berada dalam lingkungan dan budaya organisasi yang juga baik dan mendukung terhadap pengembangan diri setiap individunya. Semua aspek 
saling berkaitan, saling mempengaruhi. Inilah mengapa budaya organisasi menjadi sangat penting (Pfister, 2009).

Ada 3 tujuan utama internal control, yakni efektivitas dan efisiensi operasional, keandalan laporan keuangan, baik internal dan eksternal, serta kepatuhan atas regulasi serta kebijakan internal (Pfister, 2009). Internal control dapat dikatakan efektif jika ketiga tujuan tersebut dapat dicapai (Arens, dkk., 2012; Lakis dan Giriunas, 2012; DiNapoli, 2016; Ramdany, dkk., 2017). Dengan adanya intenal control sudah menjadi bekal awal bagi organisasi dalam membentengi diri dari potensi fraud. Kekuatan tangkal pada fraud sangat bergantung pada kualitas pengendaliannya sendiri, semakin kuat dan efekif pengendalian internal, maka potensi terjadinya fraud semakin kecil, begitu pula sebaliknya (Saputra, 2017).

Pengendalian dapat bersifat preventif untuk mencegah terjadinya fraud, detektif untuk mendeteksi fraud yang telah terjadi dan melakukan tindakan perbaikan, serta direktif unuk mengarahkan dan menyebabkan terjadinya hal yang diinginkan (Tunggal, 2013). Ketiga sifat tersebut sama-sama harus dimaksimalkan sesuai dengan tahapannya. Namun demikian, sistem pengendalian yang baik tentu akan menjadi benteng pertahanan yang kokoh untuk menghindari tejadinya penyelewengan sebelum terjadinya.

Perkembangan zaman meniscayakan kita untuk semakin terbuka akan teknologi. Dengan teknologi, keterlibatan manusia dapat semakin dikurangi sampai dengan batas-batas tertentu. Peran manusia tetap sangat vital, namun dengan kehadiran teknologi dapat semakin membantu manusia dalam memastikan sistem berjalan dengan baik. Teknologi dan sistem informasi juga merupakan salah satu sarana pendukung dalam sistem pengendalian internal (Arens, dkk., 2012; Tunggal, 2013).

Peran internal control sangat signifikan bagi sebuah organisasi, yang jika dirancang dengan maksimal akan dapat memberikan dampak positif yang signifikan bagi organisasi, namun sebaliknya jika lemah cenderung dapat dimanfaatkan sebagai pintu masuk terjadinya fraud. Karena itulah peneliti tertarik untuk mempelajarinya lebih dalam.

\section{METODE PENELITIAN}

Penelitian ini menggunakan perspektif kualitatif dengan strategi grounded theory untuk menawarkan konsep baru berdasarkan data yang diperoleh dari para informan yang telah mengalami proses, aksi atau interaksi dengan sebuah fenomena (Creswell, 2009). Penelitian dilakukan di Pondok Pesantren Salafiyah Syafi'iyah Sukorejo (P2S3). Pesantren Sukorejo dipilih karena (1) struktur organisasinya cukup kompleks dari posisi puncak sampai dengan terbawah yang tersebar di banyak bidang dan lembaga, (2) termasuk salah satu pesantren yang membuka diri pada perkembangan dunia modern, (3) masih terjaganya prinsip dan amaliyah keislaman sehingga dimungkinkan dapat ditemukan beberapa ciri khas dalam praktik kesehariannya.

Fokus penelitian adalah untuk memotret implementasi sistem pengendalian internal, menemukan fenomena penting dan kekhasan yang kental dengan muatan Islam dan menjadi nafas keseharian di Pesantren. Sumber data diperoleh melalui pengamatan, wawancara dan telaah dokumen. Informan diambil dari beberapa level struktur, terdiri atas perwakilan dari unsur pelaksana dan penanggung jawab pengelolaan keuangan di level terbawah di lembaga, bidang, hingga level pengurus harian, pengawas internal pesantren, serta Pengasuh Pesantren sebagai pemimpin tertinggi.

\section{HASIL DAN PEMBAHASAN}

\subsection{Spiritualitas}

Saat ini dunia dikuasai oleh sistem kapitalis yang menafikan nilai ketuhanan (Harahap, 2008). Pada saat yang sama, penipuan terus meningkat, menyebabkan kerugian besar bagi organisasi, individu, dan masyarakat serta menciptakan masalah moral di tempat kerja (Mahdavikhou dan Khotanlou, 2012). Zaman telah menunjukkan pergeseran nilai yang cukup signifikan, di mana nilai spiritualitas mulai dirasa sangat penting dalam paradigma manajemen terbaru. Para pakar semakin menyadari bahwa keyakinan beragama memiliki peranan yang sangat besar dalam membentuk karakter individu dan kelompok (Geigke, 2012). Pendekatan spiritual yang juga dikenal sebagai kesadaran batin, mengakui bahwa manusia bekerja tidak hanya dengan fisik semata, tetapi juga dengan hati atau roh mereka (Ajala, 2013).

Hubungan antara agama dan kerja sebenarnya bukan hal baru (McGhee dan Grant, 2008). Terlebih dalam Islam, hubungannya bukan saja ada, namun tidak terpisahkan (Muhammad, dkk., 2013). Dalam Islam, kegiatan ekonomi tidak hanya berorientasi pada 
kepentingan duniawi dan kekinian, namun juga keuntungan ukhrawi (Maksum dan Musirin, 2013).

Spiritualitas merupakan arti dan tujuan terbesar dalam hidup seseorang (Khairi, 2013) yang dianggap mampu memberikan hubungan timbal balik yang lebih positif antara organisasi dan anggotanya, serta memungkinkan semua orang untuk bekerja sama dan mencapai tujuan yang sama. Organisasi yang menjunjung nilai spiritualitas adalah yang memiliki tujuan utama dan niat luhur yang melampaui kesuksesan materi sebagai landasannya (Efferin, 2016).

Pemahaman spiritualitas dalam Islam tidak seperti pemahaman sekuler, yakni berpedoman pada petunjuk yang diberikan Allah swt., serta tidak ada pemisah antara agama dengan aktivitas sehari-hari (Khairi, 2013). Spiritualitas Islam adalah cinta yang diwarnai dan dikondisikan oleh pengetahuan dan didasarkan pada kepatuhan (Othman, 2011). Dengan mempraktikkan nilai keislaman berpotensi mengurangi korupsi dan pemborosan, mencegah fraud dan perilaku menyimpang (Khira, dkk., 2016). Hal ini dikarenakan seorang muslim dengan berbekal nilai spiritualitas yang dimilikinya akan menahan diri dari hal-hal yang dilarang oleh-Nya (Mahdavikhou dan Khotanlou, 2012). Riset menunjukkan adanya pengaruh positif dan signifikan antara religiusitas dan spiritualitas pada pencegahan fraud (Taufik, 2016; Purnamasari dan Amaliah, 2015). Perhatian pada nilai spiritualitas menjadi kekhasan utama pesantren sebagai faktor terpenting dalam semua aspek kehidupannya.

\subsection{Keyakinan dan Sikap}

Iman

Esensi spiritualitas dalam Islam adalah tauhid (Othman, 2011). Benteng iman yang kokoh akan dapat menjamin kebaikan hidup seseorang, karena iman adalah penentu aktivitas, mempengaruhi amal perbuatan, serta tujuan utama dari segala ilmu pengetahuan maupun aktivitas ibadah atau muamalah (Alim, 2011).

Sebagai hamba, keimanan dapat menjadi pondasi untuk selalu berhati-hati dalam beraktivitas karena merasa selalu dalam pengawasan-Nya, setiap perbuatann direkam secara cermat tanpa ada satu pun yang terlewatkan, yang kelak di akhirat akan dimintai pertanggungjawaban (Antonio, 2015). Iman yang benar dan kokoh berdampak pada keyakinan dan kecenderungan untuk berbuat kebaikan, mencegah fraud, dan berusaha mengurangi kesalahan akibat ketidaksengajaan (Ali, 2012).

Latar belakang keagamaan dan kepercayaan dapat mempengaruhi etika seseorang (Yesil, dkk., 2012). Iman memang tidak dapat dilihat dan disentuh dengan panca indera, namun efeknya dapat dirasakan dengan nyata. Iman yang kokoh tercermin dari kepribadian yang mulia dan amal perbuatan yang terpuji karena sikap batiniah tanpa dimanifestasikan dalam tindakan nyata menunjukkan kedustaan (Ali, 2012).

Kualitas keimanan dan ritual ibadah memiliki dampak langsung pada kualitas kinerja, karena keamanahan berangkat dari nilai ketakwaan dan ketaatan. Ketika terjadi tindakan indisipliner, pelanggaran atau pengkhianatan, berkonsekuensi pada menurunnya kualitas kesempurnaan iman seseorang. Hal ini selaras dengan sabda Kanjeng Nabi Muhammad saw., laa iimaana liman laa amaanata $l a h u$, tidak sempurna iman seseorang yang tidak beramanah (Wawancara KHR. Ahmad Azaim Ibrahimy, 17 Juli 2020).

Akhlak

Di pesantren, akhlak atau budi pekerti menjadi keharusan yang tidak dapat ditawar, bahkan dipandang jauh lebih penting dibanding pengetahuan. Pondok Pesantren adalah benteng perjuangan dalam hal akidah, tarbiyah, yang melahirkan akhlak dan keilmuan khas ahlussunnah wal jama'ah. Akhlak berhubungan dengan perbuatan baik, buruk, benar dan salah yang bersumber dari Al-Qur'an dan hadist Rasulullah saw. yang melekat dalam diri seseorang, menyatu dalam perilaku dan perbuatan (Habibah, 2015). Sebagaimana konsep Imam Al-Ghazali, akhlak adalah sifat yang tertanam dalam jiwa yang akan muncul secara spontan dan alamiah tanpa direncanakan atau dipikirkan sebelumnya (Sahriansyah, 2014).

Banyaknya skandal keuangan semakin membuka mata dunia akan pentingnya etika (Mahdavikhou dan Khotanlou, 2012). Lingkungan yang diisi oleh orangorang beretika memiliki harapan yang lebih besar untuk dapat berkembang. Seorang muslim terikat oleh iman dan akhlak dalam setiap aktivitasnya (Maksum dan Musirin, 2013).

Secara umum, terdapat perbedaan yang mendasar antara akhlak dan etika. Akhlak menggunakan parameter agama, yakni Al-Qur'an dan As-sunnah, sehingga kebenarannya bersifat mutlak dan absolut, sedangkan etika menggunakan parameter akal yang kebenarannya bersifat relatif, nisbi, dan sementara 
(Sahriansyah, 2014). Dalam Islam, akhlak dan etika tidak berbeda signifikan, karena etika seorang muslim adalah manivestasi dari akhlaknya, akal pikir seorang muslim tidak boleh bertentangan dengan panduan AlQur'an dan hadist.

\section{Amanah}

Di pesantren, nilai amanah sangat diperhatikan dalam banyak kesempatan dan forum evaluasi kelembagaan. Kualitas kinerja seseorang sangat bergantung pada kemampuannya dalam melaksanakan tugas yang diemban. Di pesantren, personalia yang mendapat tugas di suatu pos dan fungsi tertentu disebut umana' yang berasal dari kata amanah, yakni orangorang yang bertanggung jawab terhadap tugas masingmasing. Seseorang disebut amanah jika memiliki integritas untuk melaksanakan tugas dan bertanggung jawab atas perbuatannya (Othman, 2011).

Amanah adalah salah satu bentuk kecerdasan spiritual islam (Rahman dan Shah, 2015; Othman, dkk., 2014) yang meniscayakan adanya keadilan dalam memimpin, berinteraksi dan melaksanakan tugas (Khairi, 2013). Dengan sifat amanah, seorang muslim diyakini dapat memberikan kinerja terbaiknya, karena amanah dipertanggungjawabkan bukan hanya kepada manusia dan organisasi saja, tapi juga kepada Allah swt. (Dewi dan Mashar, 2019). Karena itu, sangat penting memberikan amanah kepada orang yang tepat di tempat yang tepat, orang yang benar-benar ahlinya (QS. An-Nisa':58).

\section{Sambungan Ruhani}

Dalam keyakinan dunia pesantren, sambungan ruhani dan ikatan batin antara santri dan guru sangat penting. Tidak hanya pada mereka yang masih hidup, namun tetap dijaga dengan sangat erat hingga guru-guru yang sudah wafat. Sanad itu terus besambung hingga para tabi'in, sahabat, sampai pada Kanjeng Nabi. Sambungan ruhani ini sangat penting sebagai bukti bahwa mereka berada dalam satu barisan yang sama yang terus secara istiqamah dijaga. Sambungan ruhani dapat diibaratkan seperti aliran listrik, selama sambungan daya listrik terjaga, maka lampu akan tetap menyala (Nashiruddin, 2018). Begitu juga dengan hati dan ruhani yang terus tersambung dengan para guru dapat terus menjaga hidupnya cahaya nurani, sehingga diharapkan kelak di akhirat akan dikumpulkan di surga-Nya.

Dalam interaksi sehari-hari, hubungan dan sambungan ruhani antara Kiai dan santri sangat erat layaknya orang tua dan anak (Depdikbud, 1994). Ikatan yang kuat melahirkan komitmen dan militansi.
Inilah salah satu sebab mengapa di pesantren faktor senioritas sangat kuat, karena secara karakter dan sirr ruhani mereka belum tergantikan.

\section{Barokah}

Barokah bermakna ziyadah, bertambah, atau annumuw, tumbuh, yang dapat dipahami bahwa sesuatu yang diberkahi Allah akan selalu bertambah dan menumbuhkan hal-hal positif (Fauzi, 2017). Barokah bermakna adanya nilai lebih dari apa yang dimiliki saat ini. Dengan nilai barokah, apa yang ada pada diri seseorang tidak hanya sebatas bernilai materi semata, namun juga memiliki nilai kebaikan lebih yang dapat menyebabkan pemiliknya dimuliakan di hadapan Allah swt. dan manusia (Arifin dan Zaini, 2018).

Barokah adalah simbol keagamaan dan menjadi tradisi di pesantren yang terus dilestarikan sebagai kekuatan kelembagaan (Zakiah dan Faturochman, 2004). Keyakinan pada adanya barokah menjadi salah satu kekuatan bagi umana' untuk melepaskan diri dari motivasi duniawi sebagai tujuan utamanya, sehingga dapat diharapkan tumbuh nilai keikhlasan dan ibadah dari seluruh aktivitas pengabdian yang dilakukannya. Nilai barokah diyakini dapat memberikan kebahagiaan duniawi dan ukhrawi (Budiarto, 2016).

Sejak kepemimpinan KHR. Ahmad Azaim Ibrahimy sebagai Pengasuh Pesantren, istilah gaji atau honor tidak lagi digunakan dan diganti menjadi barokah. Hal ini salah satunya bertujuan untuk semakin meningkatkan keikhlasan dan niat ibadah dalam seluruh aktivitas khidmah.

\subsection{Praktik}

Niat

Nabi Muhammad saw. bersabda bahwa seluruh amal perbuatan manusia sangat bergantung kepada niatnya. Jika diniati semata-mata karena Allah swt. dan rasul-Nya, maka akan bernilai ibadah dan bermanfaat baginya. Namun jika hanya diniati untuk kepentingan duniawi, maka yang diperoleh hanya apa yang ia kerjakan, tidak lebih, tidak ada nilai ibadah dan barokah di dalamnya. Karena itu di pesantren diajarkan, apa pun yang dikerjakan dianjurkan untuk dikaitkan dan diniati untuk ibadah agar ada nilai lebih yang akan diperoleh kelak.

Selaras dengan hal itu, budaya pesantren sangat meyakini bahwa peranan niat sangat besar terhadap kualitas dan nilai suatu perbuatan. Secara empiris juga sudah terbukti adanya kaitan dan dampak positif antara niat dengan perilaku (Wijaya, 2008; Ali, dkk., 2015; Othman dan Nazjm, 2017). Dalam Islam, posisi 
niat sangat vital dan mutlak dibutuhkan agar suatu tindakan dapat bernilai (Khairi, 2013).

Niat adalah kemauan yang kuat untuk berperilaku atau melakukan suatu pekerjaan (Ajzen, 1991; Mayasari, dkk., 2018). Niat diyakini dapat berdampak positif atas keberhasilan suatu tindakan (Ali, dkk., 2015) serta dapat menambah keyakinan keberhasilan perilaku (Mayasari, dkk., 2018), sikap (Wijaya, 2008), kepercayaan diri dan kematangan mental (Sarwoko, 2011).

Niat dilakukan di dalam hati dengan keteguhan yang kuat. Allah Maha Mengetahui yang rahasia dan tersembunyi (Hameed, 2009), apakah murni karenaNya ataukah ada motif tersembunyi. Dan salah satu nilai lebih niat adalah walaupun akhirnya perbuatan tersebut tidak dapat dikerjakan atau diselesaikan karena suatu alasan di luar kehendaknya, maka hal tersebut sudah tercatat sebagai ibadah dan berpahala baginya (Khairi, 2013).

\section{Khidmah}

Khidmah adalah prinsip pengabdian yang menjadi salah satu ciri utama di pesantren. Apa pun dan di mana pun bertugas adalah bentuk khidmah kepada pesantren dan guru yang diharapkan dapat bernilai keberkahan dan tercatat sebagai ibadah. Prinsip ini jika dilakukan dengan sungguh-sungguh dapat melahirkan sikap patuh dan loyalitas yang luar biasa, yang di pesantren dikenal dengan sam'an wa tha 'atan, apa pun yang didengar dari guru dilakukan dengan penuh kepatuhan (Arifin dan Zaini, 2018).

Khidmah bermakna memberikan pelayanan terbaik kepada pesantren dan guru dengan kepatuhan yang maksimal tanpa mengharapkan imbalan. Konsep khidmah meniscayakan adanya rasa ikhlas dalam melaksanakan tugas. Pada era saat ini, imbalan merupakan suatu keniscayaan, namun dengan doktrin khidmah, umana' diajarkan untuk tidak menjadikan materi sebagai motivasi utama. Ada ungkapan yang khas di pesantren, bede tarema tade' panarema, yang artinya jika ada ambillah, jika tidak ada terimalah dengan lapang dada.

Walaupun imbalannya tidak seberapa jika dibandingkan dengan pekerjaan sejenis di luar pesantren, tenaga khidmah di pesantren menunjukkan kesungguhan dan loyalitas dalam bekerja (Badarwan, 2018). Mereka meyakini adanya nilai barokah dari sesuatu yang didapatkan dari pengabdiannya di pesantren, termasuk adanya kemudahan mencukupi kebutuhan sehari-hari. Berkhidmah tidak semata untuk bekerja, namun lebih dari itu untuk membantu pesantren melaksanakan tugas mulia mendidik santri dan melakukan kegiatan dakwah sebagai kontribusi dalam memperjuangkan agama Allah dan bermanfaat bagi sesama umat manusia (Othman, 2011).

\section{Musyawarah}

Dalam seluruh aktivitas dan proses pengambilan keputusan, pesantren tidak pernah meninggalkan budaya bermusyawarah. Tradisi musyawarah adalah salah satu model kepribadian muslim (Othman, dkk., 2014). Dalam Islam, musyawarah adalah amalan yang mulia dan penting. Diriwayatkan oleh sahabat Abu Hurairah, bahwa beliau tidak pernah melihat seseorang yang paling sering melakukan musyawarah selain Rasulullah (Abdullah, 2014).

Dengan musyawarah, selain untuk mencari solusi terbaik, semua pihak diberi kesempatan untuk berkontribusi dan menyampaikan pendapat (Rusdi, 2014). Bahkan sepanjang masih dalam batasan materi pembahasan, karyawan diberi kesempatan untuk menyampaikan harapan dan keluhan selama bertugas, pimpinan juga dapat melakukan evaluasi dan pengarahan yang dibutuhkan sehingga semua permasalahan sebisa mungkin diselesaikan dan tidak sampai berlarut-larut (Ilyas, 2018).

Setelah proses musyawarah dilalui, semua pihak memiliki kewajiban untuk menghormati dan menaati apa pun keputusan yang dihasilkan dan ditetapkan oleh pimpinan atau pihak yang berwenang (Abdullah, 2014). Di pesantren, musyawarah dilakukan secara berjenjang sesuai dengan kebutuhan dan persoalan yang dibahas, selanjutnya menjadi kewenangan Pengasuh Pesantren untuk memutuskan berdasarkan hasil musyawarah dan kematangan spiritual beliau.

\section{Istikharah}

Salah satu kekhasan yang ada di pesantren adalah mekanisme istikharah dalam proses pengambilan keputusan. Istikharah dilakukan sebagai bentuk penghambaan, kepasrahan dan memohon petunjuk pada Allah swt. (Muhith, 2016). Istikharah dilakukan tidak hanya untuk urusan pribadi, namun juga untuk menyelesaikan persoalan organisasi dan keumatan sebagaimana dicontohkan oleh Rasulullah saw., termasuk dalam hal strategis dan bisnis (Edgar dan Henig, 2010). Salah satu metode istikharah dilakukan dengan cara melakukan shalat sunnah dua raka'at, dilanjutkan dengan dzikir dan doa tertentu, lalu membuka Al-Qur'an secara acak untuk menemukan isyarah dan hikmah di dalamnya.

Di pesantren, pengambilan keputusan strategis dilakukan secara bertahap. Dimulai dari musyawarah 
atau pengusulan secara berjenjang, hasilnya diserahkan kepada Pengasuh Pesantren untuk dipertimbangkan dan dibahas di forum pimpinan. Selanjutnya proses istikharah dan pengambilan keputusan oleh Pengasuh (Zarkasyi, 2018). Setelah proses struktural dan organisasi dilakukan, selanjutnya menyerahkan hasilnya pada kehendak Allah swt. (Al-Suwailem, 2000). Beberapa keputusan penting melalui istikharah misalnya seleksi personalia baru, seleksi pergantian pimpinan, atau keputusan strategis lainnya, termasuk keuangan dan penetapan anggaran, terutama jika ada beberapa opsi dan kondisi yang harus dipilih.

Metode istikharah dilakukan sebagai bentuk permohonan kepada Allah swt. agar diberikan jalan yang terbaik, terutama dalam keputusan yang sangat penting atau mengalami kebuntuan dalam memilih (Qutub, dkk., 2016). Pengetahuan manusia sangat terbatas dan penuh dengan hawa nafsu. Pengambilan keputusan yang dilakukan tanpa memohon petunjuk dan bimbingan Allah dikhawatirkan akan berdampak negatif dan merugikan. Metode istikharah juga bermanfaat untuk kemantapan hati dalam mengambil keputusan (Mustika, dkk., 2008).

\subsection{Manajemen}

\section{Pengasuh Pesantren}

Pengasuh Pesantren adalah sosok pemimpin tertinggi di Pondok Pesantren, bergelar kiai dan merupakan tokoh sentral. Posisinya tidak hanya sebagai pemimpin, tetapi juga sebagai guru dan teladan (Siswanto, dkk., 2013). Tanpa figur kiai, pesantren tidak mungkin bisa bertahan (Ilahi, 2014), karena selain santri dan kitab kuning, keberadaan kiai adalah ciri khas pesantren yang tidak terpisahkan (Hidayat, 2016).

Posisi Pengasuh Pesantren di lingkungan pesantren dan masyarakat sangat vital serta mempunyai wewenang dan otoritas mutlak (Depdikbud, 1994). Sifat komunikasi seperti ini dipandang cukup ideal dalam pendidikan akhlak (Hidayat, 2016). Figur Pengasuh Pesantren berperan sebagai penentu kebijakan, sosok yang kharismatik, konsisten dengan nilai-nilai perjuangan pendahulunya, mandiri, ikhlas beramal karena mengharap ridla Allah, serta senantiasa mengabdi kepada umat melalui gerakan dakwah dan sosialnya (Ibrahim, 2014).

\section{Sentralisasi}

Keberadaan kiai sebagai figur sentral, otoritatif dan pusat seluruh kebijakan (Iryana, 2015) memungkinkan pesantren untuk menggunakan pola organisasi yang tersentral pula. Dalam hal pengelolaan keuangan, Pesantren Sukorejo menggunakan sistem sentralisasi, artinya semua keuangan yang ada terpusat di pesantren (Masyhud, dkk., 2003; Hosaini, 2019). Dengan sentralisasi, pengelolaan keuangan pesantren berada di bawah kontrol Bendahara Pesantren sehingga dapat mempermudah pertanggungjawaban. Setiap lembaga yang membutuhkan keuangan, mengajukan secara tertulis sesuai dengan anggaran yang telah ditetapkan sebelumnya (Masyhud, dkk., 2003).

Saat ini, laporan keuangan pesantren menggunakan format arus kas sederhana, belum berdasarkan standar akuntansi yang berlaku umum. Namun begitu, mekanisme di pesantren telah menjunjung tinggi prinsip transparansi dan kejujuran (Arifin dan Raharjo, 2013). Untuk meningkatkan akuntabilitas, sangat penting pesantren memiliki tenaga keuangan yang berlatar akuntansi di semua lembaganya agar laporan keuangan dapat secara bertahap disusun sesuai dengan standar akuntansi dan sistem informasi keuangan yang terintegrasi (Suharjono, 2019).

\section{Salaf-Khalaf}

Salah satu kekhasan Pesantren Sukorejo adalah perpaduan antara kultur budaya pesantren dengan perkembangan dunia modern, salaf dan khalaf. Jika mengacu pada tipe pesantren sebagaimana konsep Usman (2013) yang terdiri atas tipe tradisional, modern, dan komprehensif, maka Sukorejo masuk dalam kategori pesantren komprehensif, yakni perpaduan antara tradisional dan modern. Dalam hal ini, pesantren berpegang pada kaidah al-muhaafadzotu 'alal qodiimisshoolih wal akhdu bil jadiidil ashlah, melestarikan budaya lama yang baik dan mengadopsi budaya baru yang lebih baik (Muhith, 2016).

Terbukanya pesantren pada modernitas sangat baik karena organisasi yang dapat bertahan dan berkembang adalah yang mau terbuka dan beradaptasi dengan tuntutan zaman. Awalnya pesantren hanya fokus pada pendidikan agama, kini semakin banyak dibuka pendidikan umum untuk merespon kebutuhan masyarakat. Pesantren yang dulu dikelola dengan sangat sederhana, kini semakin berkembang menyesuaikan dengan tantangan zaman dan kebutuhan masyarakat.

\subsection{Pusaka \\ Ibadah}

Ibadah adalah wujud penghambaan diri seorang makhluk kepada Tuhannya, Allah swt., suatu usaha untuk mendekatkan diri kepada-Nya (Sahriansyah, 
2014). Sudah menjadi kondrat manusia untuk beribadah sebagaimana diisyaratkan dalam Al-Qur'an, surah anNajm ayat 42. Bersama amanah dan ilmu, ibadah adalah ciri muslim yang memiliki nilai spiritualitas tinggi (Othman, dkk., 2014).

Budaya di pesantren meyakini bahwa seluruh aktifitas kehidupan dapat bernilai ibadah. Apalagi banyak aktivitas di pesantren yang secara kasat mata memang bernuansa ritual keagamaan. Ketaatan seorang santri terhadap kiai merupakan salah satu manifestasi dari khidmah yang dipandang juga sebagai ibadah (Alwi, 2013). Seluruh aktivitas apa pun jika diniati untuk ibadah dan sebagai bentuk penghambaan kepada Allah, hal yang bersifat duniawi pun akan bernilai ibadah. Dalam hal organisasi, ritual ibadah memiliki dampak langsung pada kualitas kinerja, karena keamanahan seseorang berangkat dari nilai ketakwaan dan ketaatannya.

\section{Wirid}

Zikir adalah ikhtiar menanamkan ingatan secara mendalam kepada Allah dalam hati dan pikiran agar selalu berhati-hati dan tidak lalai atas perintah-Nya. Bentuk zikir dapat berupa shalat, wirid dan doa (Junaidi, 2007). Wirid adalah amalan yang berisi bacaan zikir, doa dan amalan lain yang biasa dibaca secara rutin pada waktu tertentu (Abdullah, 2011). Zikir dan wirid yang istiqamah diamalkan merupakan ikhtiar menjaga sambungan ruhani dengan para guru supaya hati terus hidup dialiri daya listrik ruhani (Nashiruddin, 2018). Tradisi wirid terus dipertahankan sampai saat ini terutama oleh kalangan Islam Ahlussunnah Wal Jamaah, khususnya oleh Nahdlatul Ulama yang berbasis di Pondok Pesantren (Abdullah, 2011). Wirid adalah pusaka yang menjadi ciri khas pesantren yang sudah mentradisi secara turun-temurun. Wirid memiliki peran penting dalam membentuk karakter para umana' dan mengawal keruhanian pesantren secara keseluruhan.

\section{Hizib}

Hizib adalah amalan yang berisi doa-doa yang diajarkan oleh para ulama dan sholihin yang dibaca menurut waktu dan cara tertentu. Hizib diamalkan dengan tujuan tertentu, misalnya untuk membentengi diri, keluarga, dan lingkungan, saat menghadapi bahaya besar, untuk mengalahkan musuh yang mengancam, dan lain-lain (Abdullah, 2011). Budaya pesantren meyakini, barokah wirid dan hizib yang secara rutin dibaca memberikan efek positif dan perlindungan bagi pesantren dan penghuninya.

\section{Istiqamah}

Istiqāmah berasal dari kata istaqama, yastaqimu yang berarti berdiri, tegak lurus. Menurut Umar bin Khattab, istiqāmah bermakna teguhnya hati pada perintah dan larangan. Istiqāmah adalah sikap teguh dan konsiten pada ajaran agama, sehingga tidak ada kecenderungan untuk berpaling atau meninggalkannya sampai akhir hayat (Damis, 2011) sebagai salah satu ciri pribadi muslim yang mulia dan karakter orang-orang sholeh (Mulyono, 2020). Nabi Muhammad saw. bersabda bahwa istiqamah lebih utama dari seribu kemuliaan. Karna itu, di pesantren diajarkan untuk selalu berusaha melakukan kebaikan dan hal positif secara konsisten walau tidak akan mampu melakukan sepenuhnya (Damis, 2011).

Hikmah disyariatkannya istiqamah sangat banyak, di antaranya yaitu sebagai jalan keselamatan (Al- Ahqaf ayat 13, Hud:112), akan selalu didampingi oleh malaikat, tidak ada rasa takut dan sedih, serta akan mendapat balasan surga (Fussilat:30, Al-Ahqaf: 14). Dengan istiqamah kita akan memperoleh rizeki yang melimpah (Al-Jinn:16-17), dilindungi oleh malaikat atas perintah Allah (Fushilat: 31), mendapatkan hidangan surga (Fushilat:32), dikabulkannya doa (Yunus :89), mendapatkan pertolongan terbesar atas segala permusuhan (asySyuura:15), serta dapat terhindar dari perbuatan maksiat dan menyekutukan Allah (Fussilat: 6).

\subsection{Model Pengendalian Internal Pesantren}

Model pengendalian internal pondok pesantren digali dari kekhasan yang selama ini berjalan di pondok pesantren. Elemen utamanya adalah nilai spiritualitas yang melingkupi seluruh aktivitas dan prosedur di semua level organisasi. Dari elemen spiritualitas selanjutnya dirinci ke dalam empat kategori utama, yakni keyakinan dan sikap, praktik, manajemen, serta pusaka yang menjadi tradisi pesantren. Semua unsur tersebut saling terkait dan melengkapi dalam menciptakan sistem pengendalian internal di pesantren.

Kategori keyakinan dan sikap merupakan kunci bagi seluruh unsur pengendalian yang lain. Unsur utama kategori ini adalah nilai keimanan yang merupakan pondasi awal setiap amal seorang muslim. Unsur lainnya adalah akhlak, amanah, sambungan ruhani dan barokah. Keimanan seseorang akan melahirkan akhlak yang melekat dalam kepribadian. Dengan iman yang kuat dan akhlak yang mulia, akan menjadi bekal untuk dapat melaksanakan amanah dengan sebaik-baiknya. Sambungan ruhani dengan para guru, almarhumin dan salafunassholih hingga 
kepada para sahabat dan Kanjeng Nabi akan meningkatkan keyakinan dan keteguhan hati dalam berkhidmah, sehingga diharapkan ada nilai barokah yang akan diperoleh untuk kebaikannya di dunia dan akhirat. Kelima unsur ini secara simultan dapat menciptakan keyakinan dan sikap seorang muslim. Keyakinan dalam diri selanjutnya termanifestasi dalam perilaku dan tindakan.

Kategori kedua adalah praktik khas pesantren, yang terdiri atas niat, khidmah, musyawarah dan istikharah. Dalam melaksanakan amanah, yang pertama harus dibenahi dan dipersiapkan dengan benar adalah niat. Niat harus ditata semurni mungkin karena mengharap ridla Allah swt.. Niat yang baik akan berimplikasi pada kualitas perilaku dan tindakan yang dilakukan. Bertugas di pesantren adalah bentuk pengabdian dan khidmah. Doktrin ini ditanamkan agar muncul loyalitas, komitmen dan ketulusan dalam melaksanakan tugas. Prinsip musyawarah menjadi salah satu landasan utama pesantren dalam menjalankan roda organisasi. Dalam memutuskan halhal strategis, Pengasuh Pesantren selalu mengawalinya dengan cara musyawarah secara berjenjang dan proses istikharah, yakni memohon petunjuk dan bimbingan Allah swt. agar dapat mengambil keputusan yang terbaik.

Kategori ketiga adalah kekhasan manajemen di pesantren, yang paling utama adalah Pengasuh Pesantren selaku pimpinan tertinggi, baik dalam struktural maupun kultural. Hal-hal strategis diputuskan oleh beliau setelah melalui proses musyawarah dan istikharah. Keberadaan kekuatan otoritatif dalam diri Pengasuh Pesantren memungkinkan adanya manajemen yang sentralistik, salah satunya dalam hal keuangan. Di pesantren, sistem keuangannya tersentralisasi, dalam arti semua sirkulasi keuangan menyatu dan atas kendali Bendahara Pesantren serta diawasi oleh badan pengawas internal pesantren. Dalam rangka meningkatkan khidmah kepada umat, pesantren menerapkan prinsip terbuka pada perkembangan zaman dengan tetap memegang teguh tradisi para leluhur. Ini adalah perpaduan antara konsep salaf dan khalaf.

Kategori keempat adalah pusaka yang diyakini menjadi benteng dan perisai bagi seluruh elemen di pesantren, yang terdiri atas unsur ibadah, wirid, hizib dan istiqamah. Kualitas ibadah menunjukkan kualitas diri seseorang yang secara langsung memiliki dampak positif pada kinerjanya. Semua hal yang diniati ibadah akan memberikan kebaikan lebih, baik di dunia dengan tercapainya tujuan serta kebaikan di akhirat kelak. Wirid dan hizib adalah tradisi yang secara turun-temurun diwariskan dan menjadi budaya di pesantren. Wirid adalah pusaka khas pesantren yang memiliki peran penting dalam membentuk karakter para umana' dan mengawal keruhanian pesantren secara keseluruhan. Sedangkan hizib diamalkan dengan tujuan tertentu, misalnya untuk membentengi diri, keluarga dan lingkungan, untuk menghadapi bahaya, menghancurkan ancaman, dan lain-lain. Budaya pesantren meyakini, barokah wirid dan hizib yang secara rutin dibaca memberikan efek positif dan perlindungan Allah swt. kepada pesantren dan penghuninya.

Dari semua unsur tersebut, berikut ini kami gambarkan model pengendalian internal pondok pesantren, yang merupakan satu-kesatuan tidak terpisahkan dan saling menguatkan. Model ini diberi nama Pengendalian Internal Berbasis Spiritualitas (Spiritual-based Internal Control).

Adaptasi elemen Pengendalian Internal dengan konsep COSO tampak pada Gambar 1 yang memperlihatkan Model Pengendalian Internal Pondok Pesantren yang memasukkan elemen COSO menggantikan elemen prosedur dan aktivitas di semua level organisasi. Model ini dapat dipahami bahwa Model Pengendalian Internal Pondok Pesantren ini menyempurnakan konsep Pengendalian Internal menurut COSO, dengan menambahkan elemen spiritualitas sebagai lingkaran yang mendasari pelaksanaan pengendalian internal di pondok pesantren.

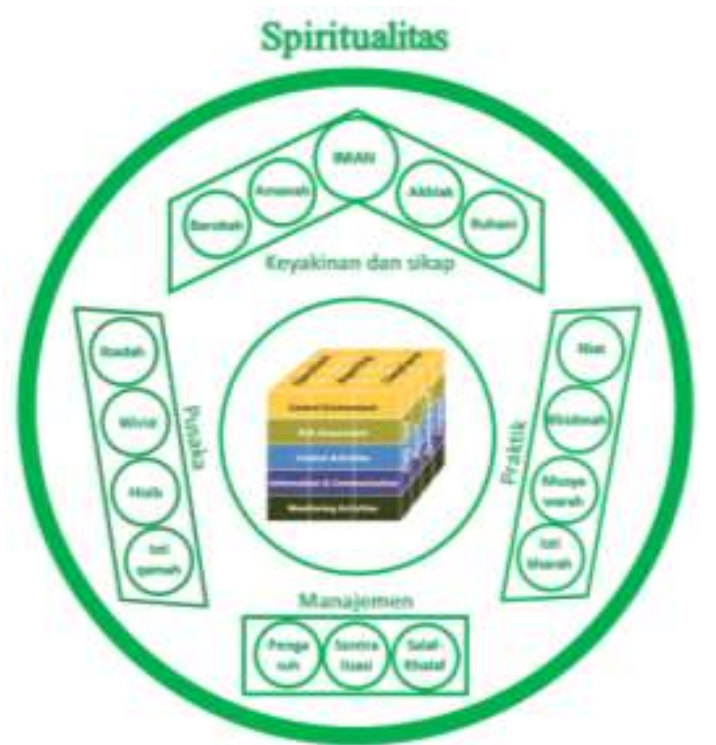

Gambar 1. Model Pengendalian Internal Pesantren Adaptasi COSO 


\section{KESIMPULAN}

Berdasarkan penelitian ditemukan bahwa ciri khas pengendalian internal Pondok Pesantren Salafiyah Syafi'iyah Sukorejo bertumpu pada nilai spiritualitas yang terdiri atas empat kategori utama, yakni 1) Keyakinan dan Sikap, terdiri atas 5 unsur, yakni: Iman, Akhlak, Amanah, Ruhani, Barokah, 2) Praktik, terdiri atas Niat, Khidmah, Musyawarah, Istikharah, 3) Manajemen, terdiri atas Pengasuh Pesantren, Sentralisasi, Salaf-Khalaf, serta 4) Pusaka, terdiri atas Ibadah, Wirid, Hizib, Istiqamah. Model ini diberi nama Pengendalian Internal Berbasis Spiritualitas (Spiritual-based Internal Control) .

\section{DAFTAR PUSTAKA}

Al-Qur'anul Karim.

Abdullah, Dudung. (2014). Musyawarah dalam AlQur'an (Suatu Kajian Tafsir Tematik). AlDaulah. Vol. 3/No. 2/Desember 2014.

Abdullah, Muhammad. (2011). Fungsi Wirid Dan Hizib Dalam Sastra Lisan Pesantren. Metasastra, Vol. 4 No. 1, Juni 2011: 38-44.

Ajala, Emmanuel Majekodunmi. (2013). The Impact of Workplace Spirituality and Employees' Wellbeing at the Industrial Sector: The Nigerian Experience. The African Symposium: An Online Journal Of The African Educational Research Network 3 Volume 13, No. 2, December 2013.

Ajzen, Icek. (1991). "The theory of planned behavior." Organizational Behavior and Human Decision Processes 50: 179- 211.

Ali, Iqbal M. Aris. (2012). Memaknai Disclosure Laporan Sumber dan Penggunaan Dana Kebajikan (Qardhul Hasan) Bank Syariah. Jurnal Akuntansi Multiparadigma Volume 3 Nomor 2, Agustus 2012.

Ali, Muhammad, Raza Syed Ali, dan Puah ChinHong. (2015). Factors affecting intention to use Islamic personal financing in Pakistan: Evidence from the modified TRA model. MPRA Paper No. 66023, posted 11. August 2015 15:33 UTC.

Alim, Muhammad Nizarul. (2011). Akuntansi Syariah: Esensi, Konsepsi, Epistimologi, dan Metodologi. Jurnal Investasi, Vol. 7 No. 2 Desember 2011.

Al-Suwailem, Sami Ibrahim. (2000). Decision Under Uncertainty: An Islamic Perspective. Riyadh Saudi Arabia: Al-Rajhi Banking And Investment Corp.. Sha'ban 1421 - November 2000.
Alwi, B. Marjani. (2013). Pondok Pesantren: Ciri Khas, Perkembangan, Dan Sistem Pendidikannya. Lentera Pendidikan, Vol. 16 No. 2 Desember 2013: 205-219 1.

Antonio, Muhammad Syafi'i. (2015). Bank Syariah dari Teori ke Praktik. Cet. Kedua. Jakarta: Gema Insani.

Arens, Alvin A., Randal J. Elder, dan Mark S. Beasley. (2012). Auditing and Assurance Services: An Integrated Approach. 14th Edition. New Jersey: Pearson Prentice Hall.

Arifin, Samsul \& Akhmad Zaini. (2018). Dakwah Inklusif Di Kalangan Bajingan: Membedah Komitmen Bekas Bajingan Dalam Membangun Peradaban Perspektif Psikologi Sosial. Jurnal Dakwah, Vol. 19, No. 1 Tahun 2018.

Arifin, Zainal, dan Ikhsan Budi Raharjo. (2013). Pertanggungjawaban Keuangan Pondok Pesantren: Studi pada Yayasan Nazhatut Thullab. Jurnal Ilmu \& Riset Akuntansi. Vol. 3. No.11.Hal.1-13

Aviana, Putu Mega Selvya. (2012). Penerapan Pengendalian Internal dalam Sistem Informasi Akuntansi Berbasis Komputer. Jurnal Ilmiah Mahasiswa Akuntansi - Vol. 1, No. 4, Juli 2012. Hal. 65.

Badarwan. (2018). Perilaku Sukarela di Pesantren: Karakter Langka di tengah Pusaran Pragmatisme SDM Lembaga Pendidikan. Shautut Tarbiyah, Ed. Ke-38 Th. XXIV, Mei 2018.

Bank Indonesia. (2018). Pedoman Akuntansi Pesantren. Cet. I. Jakarta: Departemen Ekonomi Syari'ah Bank Indonesia. Mei 2018.

Committee of Sponsoring organizations of the Treadway Commission (COSO). (2013). Internal Control - Integrated Framework. Executive Summary. May 2013. AICPA. ISBN 978-193735-239-4.

Creswell, John W. (2009). Research Design. Qualitative, Quantitative, and Mixed Methods Approaches. Third Eidtion. California: SAGE Publications. Terjemahan Achmad Fawaid. (2017). Research Design. Pendekatan Kualitatif, Kuantitatif, dan Mixed. Cetakan ke-6. Yogyakarta: Pustaka Pelajar.

Damis, Rahmi. (2011). Istiqāmah Dalam Perspektif Hadis. Al-Fikr Volume 14 Nomor 1 Tahun 2011. 
Daniela, Petrascu, dan Tamas Attila. (2013). Internal Audit versus Internal Control and Coaching. International Economic Conference of Sibiu 2013 Post Crisis Economy: Challenges and Opportunities, IECS 2013. Procedia Economics and Finance. 6 (2013) $694-702$.

Delanno, Galuh Fajar, dan Deviani. (2013). Pengaruh Kapasitas SDM, Pemanfaatan TI dan Pengawasan Keuangan Terhadap Nilai Informasi Pelaporan Keuangan Pemerintah Daerah. Jurnal WRA. Vol. 1. No. 1. Hal. 21- 46.

Departemen Pendidikan dan Kebudayaan. (1994). Nilai-nilai Budaya dalam Kehidupan Pesantren di Daerah Situbondo Jawa Timur.

Dewi, Indah Kusuma dan Ali Mashar. (2019). Nilainilai Profetik dalam Kepemimpinan Modern pada Manajemen Kinerja, Cetakan Pertama, Lampung, CV. Gre Publishing.

DiNapoli, Thomas P. (2016). Standards for Internal Control in New York State Government. Office of the New York State Comptroller. March 2016.

Djajadikerta, Hamfri. (2004). Perbandingan Pengendalian Intern dan Pengendalian Manajemen dalam Hubungannya dengan Agency Theory. Bina Ekonomi. Vol. 8, No. 1, Januari 2004: 1-109.

Dorminey, Jack, A. Scott Fleming, Mary-Jo Kranacher, and Richard A. Riley Jr.. (2012). The Evolution of Fraud Theory, Issues in Accounting Education American Accounting Association, Vol. 27, No. 2.

Edgar, Iain R. and Henig, David. (2010). 'Istikhara: the guidance and practice of Islamic dream incubation through ethnographic comparison.', History and anthropology., 21 (3). pp. 251-262.

Efferin, Sujoko. (2016). Sistem pengendalian Manajemen Berbasis Spiritualitas. Jakarta Selatan: Yayasan Rumah Peneleh.

Fauzi, Ahmad. (2017). Persepsi Barakah Di Pondok Pesantren Zainul Hasan Genggong Perspekstif Interaksionalisme Simbolik. Al-Tahrir, Vol. 17, No. 1 Mei 2017 : 105-132.

Geigle, David. (2012). Workplace Spirituality Empirical Research: A Literature Review. Business and Management Review Vol. 2(10) pp. 14 - 27 December, 2012.

Habibah, Syarifah. (2015). Akhlak dan Etika dalam Islam. Jurnal Pesona Dasar. Vol. 1 No. 4, Oktober 2015, hal 73 - 87 ISSN: 2337-9227.
Hameed, Shihab A.. (2009). Software Engineering Ethical Principles Based on Islamic Values. Journal Of Software, VOL. 4, NO. 6, August 2009.

Harahap, Sofyan S. (2008). Kerangka Teori \& Tujuan Akuntansi Syariah. Jakarta: Pustaka Quantum.

Hartadi, Bambang. (1999). Sistem Pengendalian Intern dalam Hubungannya dengan Manajemen dan Audit (Edisi 3). Cetakan Pertama. Yogyakarta: BPFE-Yogyakarta.

Hidayat, Mansur. (2016). Model Komunikasi Kyai Dengan Santri Di Pesantren. Jurnal Komunikasi Aspikom, Volume 2 Nomor 6, Januari 2016, Hlm 385-395.

Hosaini, Ahmad. (2019). Analisis Tipologi Perencanaan Kurikulum Pendidikan Pondok Pesantren Sidogiri Pasuruan, Salafiyah Syafi'iyah Sukorejo, Dan Al-Amien Prenduan. 'Anil Islam: Jurnal Kebudayaan Dan Ilmu Keislaman. Vol 12, No 2, December 2019, P. 243-263.

Ibrahim, Rustam. (2014). Eksistensi Pesantren Salaf Di Tengah Arus Pendidikan Modern. Jurnal “Analisa" Volume 21 Nomor 02 Desember 2014

Ilahi, Mohammad Takdir. (2014). Kiai: Figur elite pesantren. Ibda' Jurnal Kebudayaan Islam. Vol. 12, No. 2, Juli - Desember 2014. ISSN : 1693 6736.

Ilyas, Musyfikah. (2018). Tinjauan Hukum Islam terhadap Musyawarah dalam Penyelesaian Sengketa Ekonomi Syariah. Al-Qadau Volume 5 Nomor 2 Desember 2018.

Jensen, Michael C. dan William H. Meckling. (1976). Theory of the Firm: Managerial Behavior, Agency Costs and Ownership Structure. Journal of Financial Economics. October, 1976, V. 3, No. 4, pp. 305-360.

Junaidi, Luqman. (2007). The power of wirid. Cetakan I. Jakarta: Penerbit Hikmah.

Kasim, Dr. Nawal. (2010). Auditing from the Islamic Perspective. Kuala Lumpur: Accountants Today. June 2010. Halaman 28-31.

Kassem, Rasha, dan Andrew Higson. (2012). The New Fraud Triangle Model. Journal of Emerging Trends in Economics and Management Sciences (JETEMS). 3(3). @ Scholarlink Research Institute Journal, 2012 (ISSN: 2141-7024. Page 191-195. 
Khairi, Mohammad Shadiq. (2013). Memahami Spiritual Capital Dalam Organisasi Bisnis Melalui Perspektif Islam. Jurnal Akuntansi Multiparadigma, Volume 4, Nomor 2, Agustus 2013, Hlm 286-307.

Khira, Masrur Mohd, Abdul Kadir Othman, Muhammad Iskandar Hamzah, Nur Atiqah Rochin Demong, Emi Normalina Omar, Mohd Khalid Mohd Abbas. (2015). Islamic Personality Model: A Conceptual Framework. Fifth International Conference on Marketing And Retailing (5TH INCOMaR) 2015. Procedia Economics and Finance 37 ( 2016 ) 137 - 144.

Mustika, M. Shodiq, Rusdin S, Rauf, Indarwati Ihsani. (2008). Rahasia Shalat Istikharah, Cet, I, Yoyakarta, Mutiara Media.

Mahdavikhou, Mahdi, dan Mohsen Khotanlou. (2012). New approach to teaching of ethics in accounting "introducing Islamic ethics into accounting education". WCES 2012. Procedia Social and Behavioral Sciences 46 (2012) 1318 1322.

Maksum, Moh. Asra, dan Musirin. (2013). Pemikiran KHR. As'ad Syamsul Arifin tentang Ekonomi dalam Islam. Cetakan Kedua. Surabaya: Pena Salsabila.

Masyhud, Sulthon, Khusnuridlo, Mastuki HS., Sigit Muryono, dan Imam Safe'i. 2003. Manajemen Pondok Pesantren. Jakarta: Diva Pustaka.

Mayasari, Mega, Adi Irawan Setiyanto, dan Rusda Irawati. (2018). Pengaruh Faktor-Faktor Individual Terhadap Niat Melakukan WhistleBlowing Internal Dan Eksternal Pada Akuntan Di Batam (Studi Kasus Politeknik Negeri Batam). Jurnal Gama Societa, Vol. 2 No. 1, Mei 2018, 48-53.

McGhee, Peter, dan Patricia Grant. (2008). Spirituality and Ethical Behaviour in the Workplace: Wishful Thinking or Authentic Reality. EJBO Electronic Journal of Business Ethics and Organization Studies Vol. 13, No. 2.

Muhammad, Mohd Zulkifli, Ahmad Syakir Junoh, Ahmad Ridhuwan Abdullah, Razman Hafifi Redzuan, dan Siti Fariha Muhamad. (2013). The Concept of Business Ethics in Islamic Perspective: An Introductory Study of Small and Medium Enterprises (SMEs). Entrepreneurship Vision 2020: Innovation, Development Sustainability, and Economic Growth.
Muhith, Abd.. (2016). Konsep Pengembangan Mutu Pendidikan Pesantren. Jurnal Edukasi Vol. 08, September 2016, ISSN: 1907-4336.

Mujib, Abd. (2017). Sharia Fraud Model: The Fraud in the Circle of Faith. Proceeding The 3th International Conference on Economics, Business, and Accounting Studies (ICEBAST) 2017. Faculty of Economics and Business Universitas Jember, 24-25 November 2017. ISBN: 978-602-5617-06-8. Hal. 275-285.

Mujib, Abd. (2017). Syari'ah Fraud Model: Sebuah Konsep Dasar. Prosiding Seminar Nasional dan Call for Paper Ekonomi dan Bisnis (SNAPEREBIS) - Jember, 27-28 Oktober 2017 (hal. 112127). ISBN: 978-602-5617-01-0.

Mulyadi. (2014). Auditing. Edisi 6. Buku 1. Jakarta: Salemba Empat.

Mulyono. (2020). Keistimewaan Istiqamah Dalam Persfektif Al-Qur'an. Jurnal Imtiyaz Vol 4 No 01 , Maret 2020.

Murtanto. (2005). Sistem Pengendalian Internal untuk Bisnis. Jakarta: PT. Hecca Mitra Utama.

Nashiruddin. (2018). Pendidikan Tarekat Perspektif KH. Achmad Asrori Al-Ishaqy Dan Relevansinya Terhadap Tujuan Pendidikan Nasional. Jurnal Putih Vol III, 2018.

Nisak, Chairun, Prasetyono, dan Fitri Ahmad Kurniawan. (2013). Sistem Pengendalian Intern Dalam Pencegahan Fraud Pada SKPD Pada Kabupaten Bangkalan, Jaffa, Vol. 01 No. 1 April 2013.

Niswonger, C. Rollin, Carl S. Warren, James M. Reeve, dan Philip E. Fess. (1990). Accounting, Nineteenth Edition. South-Western College Publishing. Terjemahan Alfonsus Sirait dan Helda Gunawan. (2017). Prinsip-prinsip Akuntansi. Edisi 19. Cet. 1. Jakarta; Erlangga.

Othman, Abdul Kadir, Muhammad Iskandar Hamzah, dan Nurhazirah Hashim. (2014). Conceptualizing the Islamic Personality Model. INCOMaR 2013. Procedia - Social and Behavioral Sciences 130 ( 2014 ) $114-119$.

Othman, Nooraini. (2011). Exploring the Ummatic Personality Dimensions from the Psychospiritual Paradigm. International Journal of Psychological Studies Vol. 3, No. 2; December 2011. 
Othman, Yusuf, dan Wan nazjm. (2017). Islamic Religiosity, Attitude and Moral Obligation on Intention of Income Zakat Compliance: Evidence from Public Educators in Kedah. International Journal of Academic Research in Business and Social Sciences. 2017, Vol. 7, No. 2 ISSN: 22226990.

Pfister, Jan A. (2009). Managing Organizational Culture for Effective Internal Control: From Practice to Theory. Springer. Physica Verlag Heidelberg. Hal. 15-44.

Priantara, Diaz. (2013). Fraud Auditing \& Investigation. Jakarta: Penerbit Mitra Wacana Media.

Purnamasari, Pupung, dan Ima Amaliah. (2015). Fraud Prevention: Relevance To Religiosity And Spirituality In The Workplace. 2nd Global Conference On Business And Social Science2015, Gcbss-2015, 17-18 September 2015, Bali, Indonesia. Procedia - Social And Behavioral Sciences 211 ( 2015 ) 827 - 835.

Qutub, Sayid, Didin Hafidhuddin, dan Endin Mujahidin. (2016). Metode Pembelajaran Kepemimpinan Rasulullah SAW Kepada Para Sahabat dalam Kitab Sunan Ibn Majah. Ta'dibuna, Jurnal Pendidikan Islam, Vol. 5, No. 1, April 2016, p-ISSN: 2252-5793.

Rahman, Rashidah Abdul, dan Irda Syahira Khair Anwar. (2014). Effectiveness of Fraud Prevention and Detection Techniques in Malaysian Islamic Banks. ICGSM 2014. Procedia-Social and Behavioral Sciences. 145 (2014). Hal. 97-102.

Rahman, Zanariah Abdul, dan Ishak Md Shah. (2015). Measuring Islamic Spiritual Intelligence. International Accounting and Business Conference 2015, IABC 2015. Procedia Economics and Finance 31 ( 2015 ) $134-139$.

Ramamoorti, Sridhar, Daven Morrison, dan Joseph W. Koletar. (2009). Bringing Freud to Fraud: Understanding the State- of-Mind of the C-Level Suite/White Collar Offender Through " $A-B-C$ ", Analysis. Working paper, Institute for Fraud Prevention. West Virginia University. 22 Desember 2009.

Reding, Kurt R., Paul J. Sobel, dan Urton L. Anderson. (2013). Internal Auditing: Assurance \& Advisory Services. Third Edition. Florida: The Institute of Internal Auditors Research Foundation.
Sahriansyah. (2014). Ibadah dan Akhlak. Cetakan I,2014. Banjarmasin: IAIN Antasari Press.

Sanusi, Zuraidah Mohd, Razana Juhaida Johari, Jamaliah Said, dan Takiah Iskandar. (2015). The Effect of Internal Control System, Financial Management and Accountability of NPOs: The Perspective of Mosques in Malaysia. Dipresentasikan dalam 7th International Conference on Financial Criminology 2015, 1314 April 2015, Wadham College, Oxford, United Kingdom. Procedia Economics and Finance. 28 (2015). Hal. 156 - 162.

Saputra, Abdi. (2017). Pengaruh Sistem Internal, Kontrol, Audit Internal dan Penerapan Good Corporate Governance terhadap Kecurangan (Fraud) Perbangkan (Studi Kasus pada Bank Syariah Anak Perusahaan BUMN di Medan). Owner Riset dan Jurnal Akuntansi. Volume 1 Nomor 1, Februari 2017. Hal. 48-55.

Sarwoko, Endi. (2011). Kajian Empiris Entrepreneur Intention Mahasiswa. Jurnal Ekonomi Bisnis, Th. 16, No. 2, Juli 2011.

Siswanto, Armanu, Margono Setiawan, Umar Nimran. (2013). Entrepreneurial Motivation in Pondok Pesantren. International Journal of Business and Behavioral Sciences. Vol. 3, No.2; February 2013.

Suharjono. (2019). Pengelolaan Keuangan Pondok Pesantren. Jurnal Ekuilibrium. Vol.8.No.2. Desember 2019. Issn : 2303-0968.

Sula, Atik Emilia, Moh, Nizarul Alim, Prasetyono. (2014). Pengawasan, Strategi Anti Fraud, dan Audit Kepatuhan Syariah sebagai Upaya Fraud Preventive pada Lembaga Keuangan Syariah. JAFFA. Vol. 2 Oktober 2014. Hal. 91-100.

Suwadji. (2014). Manajemen Peningkatan Mutu Berbasis Pondok Pesantren. Edukasi. Volume 02 , Nomor 01, Juni 2014. Hal. 431-445.

Tandiontong, Mathius. (2016). Kualitas Audit dan Pengukurannya. Bandung: Penerbit Alfabeta.

Taufik, Tatung M. (2016). Pengaruh Pengawasan Dan Spiritualitas Dalam Pengendalian Perilaku Curang Ekonomi. Disertasi Program Doktoral Ilmu Ekonomi Islam. Uin Sunan Kalijaga Yogyakarta.

Tunggal, Amin Widjaja. (2013). Pengendalian Internal. Mencegah dan Mendeteksi Kecurangan. Jakarta: Harvarindo. 


\section{Jurnal Akuntansi dan Pajak, 21 (02), 2021, 320}

Wolfe, David T., dan Dana R. Hermanson. (2004). The Fraud Diamond: Considering the Four Element of Fraud. CPA Journal. 74.12 (2004):38-42.

Yakin, Nurul. (2014). Studi Kasus Pola Manajemen Pondok Pesantren Al-Raisiyah di Kota Mataram. Ulumuna Jurnal Studi Keislaman. Volume 18 Nomor 1 (Juni) 2014. Hal. 199-220.

Yesil, Salih, Zumrut Hatice Sekkeli, dan Ozkan Dogan. (2012). An Investigation into the Implications of Islamic Work Ethic (IWE) in the Workplace. Journal of Economics and Behavioral Studies Vol. 4, No. 11, pp. 612-624, Nov 2012.
Zakiah, Loubna, dan Faturochman. (2004). Kepercayaan Santri Pada Kiai. Buletin Psikologi, Tahun XII, No. 1, Juni 2004. Issn : $0854-7108$.

Zarkasyi. (2018). Pengembangan Sumber Daya Manusia di Perguruan Tinggi dan Pondok Pesantren, Studi di Institut Agama Islam Ibrahimy Sukorejo Situbondo dan Pondok Pesantren Salafiyah Syafi'iyah Sukorejo Situbondo, Disertasi, UIN Maulana Malik Ibrahim. 